\title{
The multiple signals
} assessed by female satin bowerbirds: could they be used to narrow down

\section{females' choices of mates?}

\author{
Timothy E. Robson, Anne W. Goldizen* \\ and David J. Green ${ }^{\dagger}$

\begin{abstract}
School of Integrative Biology, University of Queensland, Brisbane, Queensland 4072, Australia

*Author for correspondence (a.goldizen@uq.edu.au)

${ }^{\dagger}$ Present address: Centre for Wildlife Ecology, Department of Biological Sciences, Simon Fraser University, Burnaby, British Columbia, Canada V5A $1 S 6$
\end{abstract}

Female choice based on multiple male traits has been documented in many species but the functions of such multiple traits are still under debate. The satin bowerbird has a polygynous mating system in which males attract females to bowers for mating; females choose mates based on multiple aspects of males and their bowers. In this paper, we demonstrate that females use some cues to decide which males to examine closely and other cues to decide which males to mate with. Female visitation rates to bowers were significantly related to male size and the males' 'solitary' display rates, and, to a lesser extent, to the numbers of bower decorations. After controlling for female visitation rates, it was found that a male's mating success was significantly related to his size and the rate at which he 'painted' his bower with saliva and chewed up plant material.

Keywords: female choice; multiple signals; chemical signalling; bowerbirds; sexual selection.

\section{INTRODUCTION}

A number of hypotheses have been proposed to explain why female choice frequently leads to the evolution of multiple secondary sexual traits in males (Moller \& Pomiankowski 1993; Andersson 1994; Johnstone 1996). A recent hypothesis proposes that multiple signals help reduce mate choice costs by decreasing the number of potential mates that have to be inspected closely (Candolin 2003). Satin bowerbirds (Ptilonorhynchus violaceus) are ideal models for testing hypotheses on the evolution of multiple signals. Female satin bowerbirds make a series of visits to males before mating (Uy et al. 2001) and appear to use multiple male signals to assess potential mates. The quality of bower construction and the number and types of bower decorations influence female mate choice (Borgia 1985), as do the males' displays (Patricelli et al. 2002). Coleman et al. (2004) showed that the relative importance of different male traits depends on the age of the female and varies through the mate choice process.
In this study, we test one aspect of Candolin's (2003) hypothesis for multiple mate attraction signals by examining the signals female satin bowerbirds use when choosing bowers to visit and males with which to copulate. We investigate whether the signals that attract females to bowers differ from the signals that explain male copulation rate, as would be expected if females use one or more male signals to decide which males they should investigate more closely for the quality of another signal.

\section{MATERIAL AND METHODS}

This study was conducted in a mosaic of cleared paddocks and remnant subtropical rainforest patches adjoining the Bunya Mountains National Park $\left(26^{\circ} 51^{\prime} 54^{\prime \prime}\right.$ S, $151^{\circ} 35^{\prime} 15^{\prime \prime}$ E, Queensland, Australia). We trapped, colour-banded and measured 561 males and females. The study was conducted with approval from the University of Queensland's Animal Experimentation Ethics Committee and permits from Queensland Parks and Wildlife Service.

A total of 21 different males' bowers were monitored over three consecutive breeding seasons using six automatic video camera systems (Canon UC1000 Standard $8 \mathrm{~mm}$ Camcorders; see Borgia 1985). The field of view of each camera was approximately $80-100 \mathrm{~cm}$ wide at the bower platform. Each year we monitored 14 bowers out of the $35-50$ present. We used published correlates of male mating success (Borgia 1985) to choose bowers that had a high likelihood of being visited by females; many males' bowers are rarely visited by females.

Data on the quality of bowers and their decorations were collected at least once per month during the breeding season. The quality of the construction of the bower walls was assessed based on the density and thickness of sticks and scored from 1 to 4 ; good bowers had a high density of thin sticks and scored 4 . We also scored the symmetry of the bower walls from 1 to 4 and counted all decorations that were on display on the courts of males' bowers. Bower decorations were grouped into five categories (artificial and yellow, brown, blue and white natural). When measurements were recorded on more than one occasion per month, averages were used in analyses.

The behavioural data analysed here is from the November to December periods when the majority of copulations occurred. Bowers were monitored by video camera for $74 \pm 6 \mathrm{~h}(\mu \pm$ s.e. $)$ each month during these periods and the numbers of bouts and hourly rates of behaviours were tallied for each month. Behaviours recorded included the following: visits by females to the bowers; copulations; singing and dancing displays by the owner to females; 'solitary' displays by the owner when no other bird was in the video camera's field of view; bower painting by the owner, during which males coated the inside of the avenue with a masticated mix of saliva and hoop pine leaves and stealing of decorations and/or destruction of the bower by rival males.

We used a statistical modelling approach to investigate which signals influenced female visitation rate to bowers and male copulation success in November and December. Variation in male copulation success was primarily described by whether a male copulated or not. We therefore scored males as successful (copulated at least once in the month) or unsuccessful. We modelled female visitation rates using restricted maximum likelihood mixed models (REML) and copulation success using a generalized linear mixed model (GLMM) in Genstat 5.3 (Genstat 5 Committee 1997). In all models, the identities of bower owners were included as a random effect to control for repeated sampling at bowers. Male display rate to females was highly correlated with female visitation rate (Spearman $\rho=0.923, p=<0.0001, n=20$ bowers), as expected, and was not included in analysis of the potential factors that influenced female visitation rate. Initial models included 12 explanatory variables. These were year, month, tarsus length, bower quality (sum of symmetry and quality scores), the five decoration categories, the rates of painting and stealing and/or destruction by rivals. In addition, solitary display rates were included in the model examining female visitation rates and the proportion of visits in which males displayed to females was included in the model examining male copulation success.

Final models were selected using backward elimination of nonsignificant terms until the models only included terms whose elimination would significantly decrease the explanatory power of the models. The significance of terms in the REML models was tested by the change in model deviance. In the GLMM models the significance of terms was tested when the term was fitted last in 
Table 1. Restricted maximum likelihood mixed model (REML) of the factors that affected the number of female visits per hour at bowers.

\begin{tabular}{|c|c|c|c|c|c|}
\hline model term & effect size & s.e. & $\chi^{2}$ & d.f. & $p$ \\
\hline \multicolumn{5}{|l|}{ terms included in final model } & \\
\hline \multicolumn{6}{|l|}{ year } \\
\hline $1996 / 97$ & 0.0 & 0.034 & 6.5 & 2 & 0.04 \\
\hline $1997 / 98$ & 0.220 & & & & \\
\hline $1998 / 99$ & 0.0815 & & & & \\
\hline \multicolumn{6}{|l|}{ month } \\
\hline November & 0.0 & 0.029 & 15.1 & 1 & 0.0001 \\
\hline December & -0.117 & & & & \\
\hline tarsus length & 0.023 & 0.012 & 3.9 & 1 & 0.05 \\
\hline solitary display rate & 0.180 & 0.046 & 13.7 & 1 & 0.002 \\
\hline blue natural decorations & 0.0011 & 0.0006 & 3.6 & 1 & 0.06 \\
\hline white natural decorations & 0.0014 & 0.0007 & 3.5 & 1 & 0.06 \\
\hline yellow natural decorations & -0.0005 & 0.0002 & 7.0 & 1 & 0.008 \\
\hline
\end{tabular}

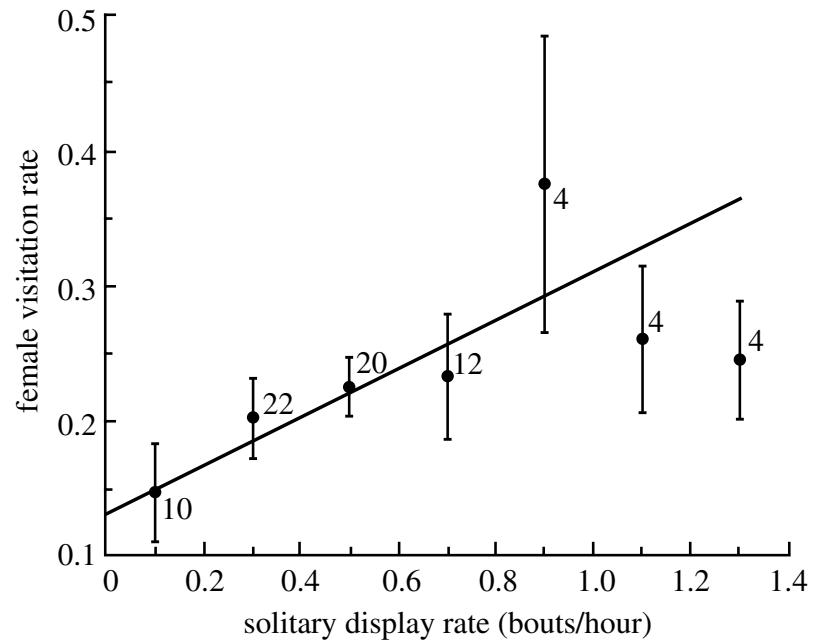

Figure 1. Number of solitary displays given by males per hour and number of female visits to males' bowers per hour. Fitted line shows the expected values produced by the mixed model (REML). Dots show mean number of female visits per hour, with error bars representing \pm s.e., for each category of solitary display rate. Numbers next to the dots show numbers of data points. Data are from November and December only and were pooled across the three years.

the model using the Wald $\chi^{2}$ statistic (Genstat 5 Committee 1997). All main effects dropped from the models were back-checked to avoid any confounding effects of deletion order. In analyses, the assumptions of the mixed models were confirmed using residual plots and, where appropriate, normal probability plots to test for unequal variance and deviations from normality among residuals. Finally, we tested for interactions between significant main effects and year to test whether effects were consistent across years.

\section{RESULTS}

During this study, we recorded an average of 17 female visits to each bower per month (range 0-134) during a total of $5550 \mathrm{~h}$ of video recordings. The rate of visitation by females averaged 0.22 an hour (range $0-0.64)$. An average of 1.8 copulations per month (range $0-15 ; n=138$ ) were observed at bowers, with the copulation rate averaging 0.03 an hour (range $0-0.11$ ). Of the 14 males studied each year, the most successful male each year performed $16 \%$ (8 of 49 ), $25 \%$ (19 of 76 ) and $23 \%$ ( 3 of 13 ) of the copulations, respectively.

\section{(a) What attracts females to bowers for closer} inspection?

Male size (tarsus length) and their solitary display rate had strong positive effects on female visitation rate (table 1; figure 1). Visitation rate also varied between years and months and was influenced by the number of bower decorations. Visitation rate was positively related to the number of blue and white natural decorations and negatively related to the number of yellow natural decorations (table 1).

\section{(b) What determines whether a female mates with a male that she inspects?}

After controlling for the number of females that visited the bower, male copulation success increased significantly with bower painting rate and tarsus length (figure 2; table 2). Copulation success also varied between years. No other explanatory term had a significant effect on copulation success. Addition of solitary display rates to the variables tested in this model did not improve the model or alter the findings about the importance of male size and painting rate.

In both models, none of the interactions between the significant main effects and year were significant, showing that these effects were consistent across years.

\section{DISCUSSION}

Female satin bowerbirds at the Bunya Mountains seem to use a male's size and the rate at which he exhibits solitary displays to decide whether to approach his bower, at which point his size and painting rate appear important in their decision about whether to mate with the male. The significance of the analysis that female visitation patterns are related to males' solitary displays, which incorporate dance and vocal elements, suggests that these function as longer distance signals to attract females to bowers. Similar cases of multiple cues being used sequentially 


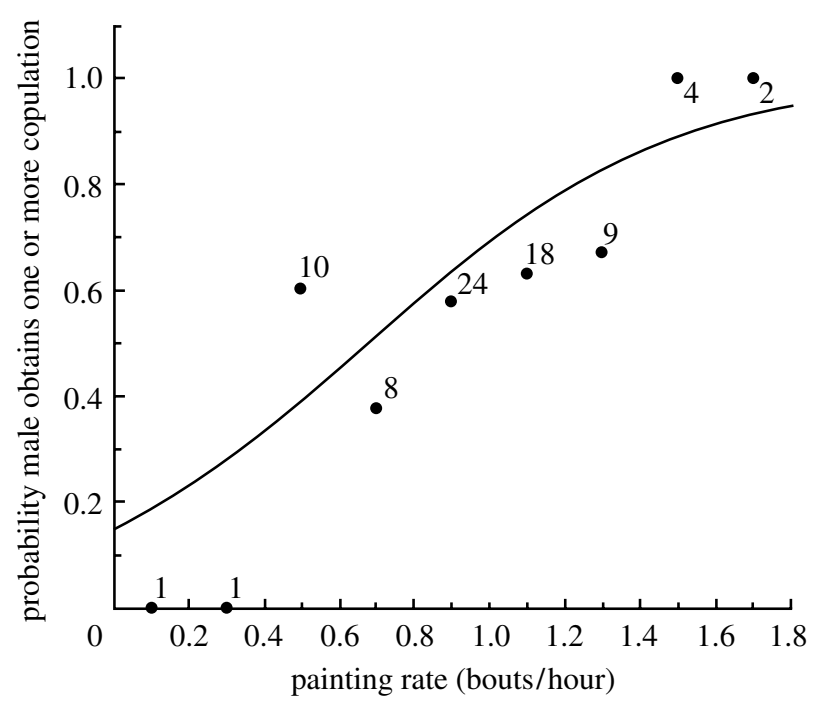

Figure 2. Binomial probability of a male copulating at least once during November and December in the period when bowers were monitored, as predicted by the owner's painting rate per hour. Predicted values were calculated from GLMM model (table 2). Dots show the observed percentage of males that gained at least one mating for each category of painting rate in a given month. Numbers next to the dots show numbers of data points. Data were pooled across the three years.

in mate choice have been documented in a few other species. For example, female fiddler crabs (Uca annulipes) choose to approach the burrows of larger males; they then decide whether to mate after investigating the quality of a male's burrow (Backwell \& Passmore 1996). In two lekking bird species, different characteristics of males have been found to predict visitation rates of females to males' courts or perches and males' copulation success (Andersson 1989; McDonald 1989). Female visitation rates were most correlated with males' rates of advertising calls in long-tailed manakins (Chiroxiphia linearis) and with males' display rates and attendance at the lek in Jackson's widowbirds (Euplectes jacksoni). In contrast, copulation rates were best predicted by the duration of one type of flight display in the former species and by tail length in the latter species.

The effect of bower decorations on female visitation rate varied, depending on their colour. Blue and white natural decorations, which were the least common types of decorations on bowers in this study, had marginally significant positive effects on visitation rate. Intriguingly, artificial decorations, which were usually blue, had no effect on female behaviour. After controlling for other decorations, yellow natural decorations, which were the most common decorations on bowers, had a negative effect on female visitation rates. This suggests that females are not attracted to bowers with a disproportionately large number of these decorations.

The quality of bower construction had little effect on female behaviour in our study. In contrast, Borgia (1985) found that aspects of bower construction were correlated with male copulation success. We may have underestimated the importance of bower construction and bower decorations by studying only the best
Table 2. General linear mixed model (GLMM) of the factors that affected copulation success, measured as whether males copulated at least once during November and December in the time period when bowers were monitored.

\begin{tabular}{lrllll}
\hline model term & effect size & s.e. & $\begin{array}{l}\text { Wald } \\
\text { statistic }\end{array}$ & d.f. & $p$ \\
\hline $\begin{array}{l}\text { terms included in final model } \\
\text { constant }\end{array}$ & 0.3997 & & & & \\
$\begin{array}{l}\text { number of } \\
\quad \text { female visits }\end{array}$ & 0.0561 & 0.026 & 4.7 & 1 & 0.03 \\
$\quad$ in a month & & & & & \\
year & & & & & \\
$1996 / 97$ & 0.0 & & & & \\
$1997 / 98$ & 0.785 & 0.692 & 6.6 & 2 & 0.04 \\
$\begin{array}{l}1998 / 99 \\
\text { tarsus length }\end{array}$ & -1.066 & & & & \\
painting rate & 0.711 & 0.266 & 7.1 & 1 & 0.008 \\
\hline
\end{tabular}

bowers in the study area. The differences between the two studies may also be explained by differences in the way the density, thickness and symmetry of sticks in bowers were subjectively categorized.

Males' mating success appeared to be related to their size and painting behaviour when the visitation rates of females were controlled for. The paint formed a visible coating on the sticks of the bower that was often over $0.5 \mathrm{~mm}$ thick but did not function as structural 'glue'. It is not yet known whether bower paint functions as a visual or a chemical signal, but the fact that females nibble at paint (presumably tasting it, since they can be seen swallowing on the videos; T. Robson, unpublished data) suggests a chemical function. If paint were shown to function as a chemical signal to females, this would be only the second documented case of an olfactory social signal in birds (Hagelin et al. 2003). Thus, bowerbirds may use a diversity of auditory, chemical and visual cues to select mates. These results and those of Coleman et al. (2004) show that mate choice in satin bowerbirds is extremely complex and that this species is an ideal subject for the study of the evolution of multiple signals.

We thank Michael and Kim Stirling for allowing us to work on their property, the Queensland Parks and Wildlife Service rangers at the Bunya Mountains for their support and Kelly Robertson and many volunteer field assistants for their help with fieldwork. Funding for this study was provided by the Australian Research Council and the University of Queensland. We thank David Putland and Mark Blows for comments on earlier versions of the manuscript.

Andersson, M. 1994 Sexual selection. Princeton University Press.

Andersson, S. 1989 Sexual selection and cues for female choice in leks of Jackson's widowbird Euplectes jacksoni. Behav. Ecol. Sociobiol. 25, 403-410.

Backwell, P. R. Y. \& Passmore, N. I. 1996 Time constraints and multiple choice criteria in the sampling behaviour and mate choice of the fiddler crab, Uca annulipes. Behav. Ecol. Sociobiol. 38, 407-416. 
Borgia, G. 1985 Bower quality, number of decorations and mating success of male satin bowerbirds (Ptilonorhynchus violaceus): an experimental analysis. Anim. Behav. 33, 266-271.

Candolin, U. 2003 The use of multiple cues in mate choice. Biol. Rev. 78, 575-595.

Coleman, S. W., Patricelli, G. L. \& Borgia, G. 2004 Variable female preferences drive complex male displays. Nature 428, 742-745.

Genstat 5 Committee 1997 Genstat 5, release 4.1: command language manual. Oxford: Numerical Algorithms Group.

Hagelin, J. C., Jones, I. L. \& Rasmussen, L. E. L. 2003 A tangerine-scented social odour in a monogamous seabird. Proc. R. Soc. B 270, 1323-1329. (doi:10.1098/rspb. 2003.2379.)
Johnstone, R. A. 1996 Multiple displays in animal communication: 'backup signals' and 'multiple messages'. Phil. Trans. R. Soc. B 351, 329-338.

McDonald, D. B. 1989 Correlates of male mating success in a lekking bird with male-male cooperation. Anim. Behav. 37, 1007-1022.

Moller, A. P. \& Pomiankowski, A. 1993 Why have birds got multiple sexual ornaments? Behav. Ecol. Sociobiol. 32, 167-176.

Patricelli, G. L., Uy, J. A. C., Walsh, G. \& Borgia, G. 2002 Male displays adjusted to female's response: macho courtship by the satin bowerbird is tempered to avoid frightening the female. Nature 415, 279-280.

Uy, J. A. C., Patricelli, G. L. \& Borgia, G. 2001 Complex mate searching in the satin bowerbird (Ptilonorhynchus violaceus). Am. Nat. 158, 530-542. 